\title{
Pedro José Pradillo, un culto artista conceptual.
}

\section{Sobre la exposición 'Con qué objeto'. Guadalajara, septiembre-octubre 2019}

Pedro José Pradillo, a conceptual artist cult.

About the exhibition 'With what purpose'. Guadalajara, September-October 2019

\section{JosÉ MIGUEL MUÑOZ JIMÉNEZ (1) 0000-0001-8215-5361}

Universidad Francisco Marroquín, Ciudad de Guatemala, Guatemala.

\section{Resumen}

La principal característica que se observa en la madura producción de Pedro José Pradillo, reflejada en la exposición de 2019 en Guadalajara, al margen de sus períodos constructivistas, es su fidelidad al arte conceptual; también el profundo análisis que aborda sobre el significado del arte -en particular del elaborado en el siglo XX-, y acerca del papel de la cultura en la sociedad occidental. Su interés, como en cualquier otro artista de ese movimiento, se centra en lograr imágenes y objetos para la fascinación a partir de la combinación de elementos encontrados que, más allá de la particular estética resultante, susciten inquietudes no deseadas en el espectador y provoquen en él motivos para la reflexión. Sus ensamblajes le sitúan, al mismo tiempo, dentro de la corriente del arte objetual.

Artículo original Original Article

Correspondencia/ Correspondence José Miguel Muñoz Jiménez josemiguelmunoz@ telefonica.net

Financiación/Fundings Sin financiación

Received: $13 \cdot 10.2020$ Accepted: 29.12 .2020

CÓMO CITAR ESTE TRABAJO / HOW TO CITE THIS PAPER

Muñoz, J. M. (2020). Pedro José Pradillo, un culto artista conceptual. Umática. Revista sobre Creación y Análisis de la Imagen, 3. https://doi.org/10.24310/Umatica.2020.v2i3.6769

Umática. 2020; 3:113-134 
Pedro José Pradillo, a conceptual artist cult. About the exhibition 'With what purpose'. Guadalajara, September-October 2019.

\title{
JosÉ MIgUEL MUÑOZ JIMÉNEZ
}

Universidad Francisco Marroquín, Ciudad de Guatemala, Guatemala.

\begin{abstract}
The main characteristic observed in the mature production of Pedro José Pradillo, reflected in the 2019 exhibition in Guadalajara, regardless of his constructivist periods, is his fidelity to conceptual art; also the deep analysis that deals with the meaning of art - in particular that elaborated in the twentieth century - and the role of culture in Western society. His interest, as in any other artist of that movement, focuses on achieving images and objects for fascination from the combination of elements found that, beyond the particular aesthetic resulting, raise unwanted concerns in the viewer and cause He reasons for reflection. His assemblages place him, at the same time, within the current of object art.
\end{abstract}

KEYWORDS: Pedro José Pradillo; Conceptual art; Object art; exhibition in Guadalajara; year 2019.

Summary - Sumario

1. Introducción

2. La importancia del conceptualismo de Pradillo como neovanguardia, y de sus raíces barrocas

3. Etapas recogidas en la exposición de septiembre-octubre de 2019

4. Los dos grandes proyectos "Besos y Caprichos" y "Ecce Homo. A propósito de Nietzsche"

5. Conclusión: un arte culto para pensar. Neo-POP y Post-posmoderno 


\section{Introducción}

En la carrera artística de Pedro José Pradillo, personaje humanista de variados registros $^{1}$, hubo un par de exposiciones en su ciudad de Guadalajara que fueron decisivas a la hora de darse a conocer, y que contribuyeron a su maduración como creador: la primera, memorable, fue aquella celebrada en las salas manieristas del Palacio del Infantado, en 1996, y en la que las cajas neopop del artista se maridaron con las pinturas del Cincinatto y con los azulejos talaveranos de los zócalos; entonces, un Pradillo de 37 años de edad irrumpía con cierto estrépito y gran éxito de crítica en el reducido escenario local ${ }^{2}$. Con ella, llena de resonancias entre dadás y surrealistas, la vía del ensamblaje enmarcado por los límites del paralelepípedo, se le mostró al autor como un formato más que válido, muy prometedor.

Veinte años después, en 2016, otra muestra muy importante en el salón de exposiciones de Ibercaja de Guadalajara se basó en la exhibición de un nutrido conjunto de obras de su proyecto "Besos y Caprichos", ya iniciado dos años atrás ${ }^{3}$, y en el que Pradillo volvió a mostrar su maestría ya consolidada, propia de su bagaje intelectual y de su edad próxima a los sesenta años.

Entonces, la importancia y el éxito cosechado entre los entendidos le llevaron a dar el salto que supone para cualquier artista el exponer en Madrid obra en solitario. Fue en el año de 2017 la presentación en Art Room. Espacio de arte de su nuevo proyecto "Ecce Homo. A propósito de Nietzsche", reválida definitiva de cómo se puede y debe sostener un arte conceptual basado en un sólido cimiento ideológico, moral y filosófico ${ }^{4}$. El triunfo entre los visitantes fue patente, y la muestra se repitió con igual resultado en exhibiciones individuales en

1. Pedro José Pradillo Esteban (Guadalajara, 1959), es licenciado en Filosofía y Letras (1987) y Doctor en Historia (2003) por la Universidad de Alcalá de Henares. Además posee el Primer Grado de Especialización en Gestión del Patrimonio (1999). Desde 2005 es Técnico de Patrimonio Cultural del Patronato Municipal de Cultura del Ayuntamiento de Guadalajara. Su currículo ha derivado por dos caminos convergentes: uno, hacia la creación artística, exhibiendo sus obras en diversas muestras individuales y colectivas desde 1980; y, otro como historiador e investigador, que se ha desarrollado a través de múltiples trabajos de documentación, y materializado en múltiples exposiciones de divulgación del patrimonio histórico-artístico y cultural de Guadalajara, por él organizadas y comisariadas. Asimismo, la nómina de sus publicaciones en forma de libros, artículos en revistas científicas y comunicaciones a congresos es muy amplia.

2. MUÑOZ, J. M. (1996).

3. Conviene saber que este proyecto de interpretar desde el siglo XXI los grabados de Goya se planteó para ser realizado en el curso de cuatro años, entre 2014 y 2018, y que habría de estar formado por un conjunto de ochenta cajas-collage diferentes, una por cada uno de los Caprichos del aragonés. Con un ímprobo esfuerzo, Pradillo cumplió exactamente su objetivo, presentando la mayor parte de sus escaparates en conjuntos parciales, además de en la muestra de Guadalajara de 2016: estuvo presente con una selección de ellas en las exposiciones de Madrid, en la galería Modus Operandi y en Jazz Madrid, así como en otra presentación con obras nuevas en el Teatro-Auditorio de Móstoles, en el año 2018. Con todo aún falta la exhibición completa de tan fabuloso conjunto conceptual.

4. MUÑOZ, J. M. (2018).

Umática. 2020; 3:113-134 
el Auditorio Municipal de Cuenca, en el Museo Zabaleta de Quesada (Jaén) y en la misma Guadalajara, en este caso en el marco histórico de otro palacio conservado en la ciudad, hoy dedicado a Biblioteca Pública.

Ahora con este artículo -centrado sobre todo en la última exposición antológica de Pradillo que se celebró, con éxito de público y crítica, entre el 4 de septiembre y el 11 de octubre de 2019 en la sala de exposiciones de la Diputación Provincial de Guadalajara5-, quiero analizar la revisión panorámica de una carrera que ya es larga, pero que sigue la línea ascendente del crecimiento propio de un trabajo exhaustivo, y de un empuje todavía juvenil. Al tratarse de una retrospectiva, su selección se hizo buscando reflejar lo mejor posible la mayor parte de las etapas que a lo largo de más de cuarenta años ha desarrollado la obra de Pradillo. Con todo por razones de espacio quedaron fuera algunos momentos no menos interesantes.

A la vez, se presentaron al público tres obras objetuales totalmente inéditas, aunque incardinadas en alguno de los proyectos más recientemente realizados: el ensamblaje "Carcajadas baratas", de 2016 y próxima a alguna obra del ciclo Ecce Homo; la jaula que encierra "Un mirlo blanco", del mismo año y deudora de la última manera de operar conceptualmente el autor después de Besos y Caprichos, y finalmente el inclasificable panel-instalación "¿Nostalgia de qué...?", monumental obra que había sido realizada ex profeso para esta ocasión. Ante su brutal presencia y dimensiones $(230 \times 350 \times 60 \mathrm{~cm})$, se puede asegurar que Pradillo nos está hablando del más grave y actual problema de nuestra nación española: la difícil recomposición de sus jirones desgarrados.

En razón de que su obra todavía no ha llegado a los museos ni a las grandes colecciones, ni ha sido llevada a los eventos periódicos del arte contemporáneo, nuestro estudio se ha de limitar a lo que se dio a conocer en las citadas exposiciones de la carrera de Pedro José Pradillo, así como a partir de varias visitas a su taller.

\section{La importancia del conceptualismo de Pradillo comoneovanguardia y de sus raíces barrocas}

Se podría insistir en otras muchas cuestiones, como la dimensión que alcanza en el artista el interés por desmitificar modelos de comportamiento, obras o personajes encumbrados; la asimilación de conceptos surgidos en los circuitos marginales urbanos, o la subversión como práctica de acción frente a conceptos básicos del arte clásico, pero, también, de la cultura de masas ${ }^{6}$. En definitiva, dentro de una corriente postmoderna de acentuado estilo

5. MUÑOZ, J. M. (2019).

6. Tal vez por ello la etiqueta de conceptual es un totum revolutum en que todo cabe, pues en palabras de KOSUTH, J. (1969), uno de los intelectuales emblemáticos del fenómeno: "...lo que el arte tiene en común con la lógica y las matemáticas es que también es una tautología; es decir, la idea artística ( u obra) y el arte son lo mismo". También se ha dicho que el arte conceptual, síntoma de globalismo al fin y al cabo, lleva el minimalismo dadá-constructivista un paso más allá, hasta la consideración del arte como una tumba. Pero como señala irónicamente PERREAULT, J. (1971): "...si el arte conceptual no es fotogénico, al menos sus artistas sí lo son, y mucho. 
neo-pop, las bizarrías de Pedro José Pradillo se revelan muy próximas a las de otros artistas difíciles de clasificar, pero tan valorados a nivel internacional como Wolf Vostell, Joseph Cornell, Louise Nevelson o Willie Bester, todos deudores, como el alcarreño, del gran maestro dadá Kurt Schwitters.

Además de conceptual, la obra de Pradillo debe ser enmarcada por múltiples razones dentro del llamado pop art en su variante objetual; ello en su más tardía y actual versión que se podría denominar neopop, pues ya es posible calificarla así en cuanto hace más de medio siglo que la recuperación de lo icónico y del "nuevo realismo" se llevó a cabo en la obra de los británicos y norteamericanos Oldenburg, Jasper Johns, Rosenquist o Rauschemberg, sin olvidarnos del más mediático, si cabe, Warhol.

Mas no debemos entrar en difíciles disquisiciones sobre si el auge actual del neopop no es más que la continuidad del movimiento sesentero que vino a romper con la hegemonía del expresionismo abstracto, o se trata de una nueva lectura tras unos años de decadencia del estilo, debida a la paulatina desaparición de sus creadores. Tal vez ello coincidió con la clara situación de pluralidad de los años de auge de lo postmoderno, en los finales -no de la historia en el sentido provocativamente anunciado por Fukuyama-, sino del siglo y del milenio. Esos últimos treinta años en los que parecían imponerse el minimalismo, la arquitectura débil, otras mil tendencias y, de nuevo, la abstracción plástica en grandes formatos. Fue lo que se llegó a llamar las neovanguardias y demás? y cuando daba la impresión de que se despreciaban las aportaciones pop en favor de nuevos modos de hacer arte, excesivamente relacionados con la revolución tecnológica, con los nuevos materiales y con el arte callejero, ya fuera el basado en formas tradicionales como los grafitti o el muralismo urbano, o en las perfomances, las instalaciones y cualquier otra manifestación de lo efímero o del no-arte más o menos conceptual.

Otro aspecto que puede llegar a fascinar a quien intente interpretar la obra conceptual de Pradillo, es que en sus creaciones muchas veces lo barroco se impone a cualquier otra categoría histórica. Lo barroco, como bien defendió el tardorromántico D’Ors, es una condición propia de genios creadores. Con este estilo se llegó por vez primera a la obra de arte total, a la que reúne o pretende aunar todas las artes, que es precisamente lo que resalta a escala reducida en los escaparates, llenos de elementos en apariencia casuales, de Pedro Pradillo.

Como ven no todo está perdido". Nótese que esa fotogenia también la encontramos en la obra y en la persona de Pradillo.

7. Aunque soy consciente de que el vanguardismo histórico no fue más que una ilusión producida por el Ethos de progreso que caracterizó los cambios técnicos del siglo XIX. En palabras de BURNHAM, J. (1977): "...actualmente el vanguardismo sólo puede tener sentido como recuperación, como inaceptable iconoclasia, como presentación deliberada de no-arte", y más adelante:"...A todas luces ha dejado de ser importante que uno sea buen o mal artista: la única cuestión pertinente es -como ya han empezado a entender algunos jóvenes- ¿por qué no somos todos artistas?". A este respecto, según BATTCOCK, (ed.) (1977), el arte conceptual que ya no puede ser definido como una mercancía, ni siquiera como un hecho físico provisto de algún valor económico, es la forma de arte más inaceptable, proponiendo incluso bautizarlo con el nombre de arte forajido.

Umática. 2020; 3:113-134 
Tal vez todo responda a que su propia personalidad está imbuida del Barroco, por ser moderna, rica y complicada.

Se trata pues de toda una tradición persuasiva, propia de la retórica del sermón como género literario y recurso pastoral, que Pradillo estudió con rigor en muchos ejemplos del ámbito guadalajareño, y que ha modificado sus formas de convencimiento doctrinal, a veces por cierto tan estrictas que nuestro artista más parece luterano que católico romano. Desde su investigación para doctorarse en 2004, Pradillo conoce y maneja una bibliografía sobre emblemática que es cada vez más amplia. Por ósmosis, todo ello sale e impregna sus creaciones aparentemente más irreverentes. Podemos citar algunos ejemplos espigados de sus versiones de Besos y Caprichos.

En algún caso opta por la vanitas barroca, de claro origen petrarquista y por tanto ortodoxa. Sabe Pradillo que la coexistencia de los objetos, simplemente por contigüidad, cambia notoriamente tanto su significado conceptual aislado, de cada uno, como de todo el conjunto. Surgen así esos emblemas, adivinanzas o jeroglíficos de difícil interpretación.

Otrora se inclina al diseño de construcciones en forma de catafalco, o capelardentes de innegables raíces barrocas. Son sus cajas con aspecto de ataúd. Son esas cajas con forma de altar, donde domina el expositorio o manifestador. Donde sorprende la movilidad y lo envolvente.

Lo cierto es que la estética predominante en sus piezas está llena de referencias y estilemas propios del barroco: el uso de espejos, de oros y de oropeles, combinados a veces con transparentes y claraboyas en busca de contrastes lumínicos; otrora de elementos propios de las tramoyas y artefactos de tipo teatral, cuando el escaparate alcanza un desarrollo escénico complejo, con bambalinas, pantallas y espacios adyacentes sugeridos.

Pero no todo es apariencia. Es un paralelismo claro con lo goyesco: de cómo la calidad estética y técnica de sus obras se somete en general a la importancia histórica, testimonial, de sus temáticas.

\section{Etapas recogidas en la exposición de septiembre-octubre de 2019}

Las obras más antiguas fueron tres "juguetes" del año de 1975 que se expusieron en la primera exhibición de Pradillo en Guadalajara de 1980, y que son piezas elaboradas con tubos de polietileno ensamblados, componiendo divertidos muñecos con elementos de plástico desechados. Hoy los vemos como los primeros gritos expresivos de un quinceañero que balbuceaba su creatividad con esos pedazos inútiles que en otras manos hubieran acabado en el cubo de la basura. También hizo por entonces unas tallas más abstractas y de marcado carácter arquitectónico, que no se expusieron por falta de espacio, con fragmentos de vigas de madera recuperadas de derribos.

Seguían en orden cronológico, y fueron absoluta novedad tres fotomontajes de 1977-79, pero positivados en lambda sobre dibond expresamente para esa muestra, y que realizados por el artista con menos de veinte años sorprendieron al público por su fuerza, riqueza cro- 


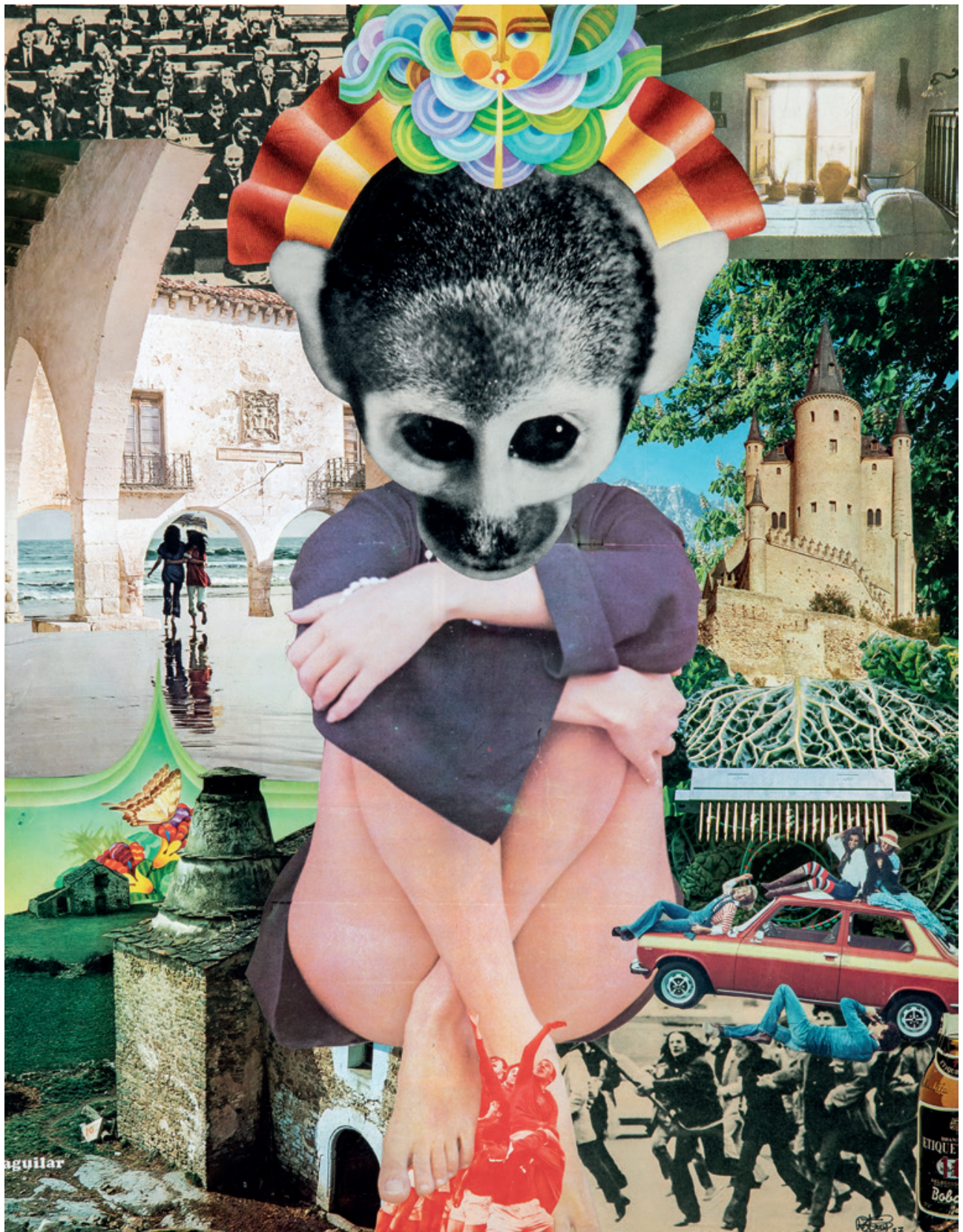

mática y visión plenamente pop y propia de un joven aún bachiller, y en los que se anticipaban las obsesiones que el posterior Pradillo conceptual vuelve a convertir en el leit motiv de todas sus obras actuales, llenas de denuncia social marcada por el tono satírico bien suavizado por el humor, la imagen surreal e incluso la búsqueda de la belleza estética.

Tales collages se pueden resumir en el reflejo de la visión de un precoz maestro en un delicado momento de la historia contemporánea de España. Por cierto que en el siguiente mes de octubre de 2019, en la sala Modus Operandi de Madrid, Pradillo presentó la casi totalidad de los fotomontajes de aquellos precoces años, como nueva prueba de su actividad.
Fig.o1.

Composición-10 ¿Qué Piensas? 1977. Collage de fotografías impresas sobre papel, $60 \times 53.5 \mathrm{~cm}$. 
Seguidamente, los primeros ochenta se tradujeron en una reducción del tamaño de las obras, que al tiempo eran fruto del continuo estudio de los movimientos de vanguardia -Dadaísmo, Surrealismo, Futurismo, Constructivismo,...-, así como el detenido análisis de la obra de sus principales exponentes propiciaba en él una revisión crítica de la función y del concepto de arte, abordando una obra de tesis basada en la desmitificación del lenguaje y de los grandes hitos de la modernidad, desde una peculiar perspectiva irónica basada en el ready-made. También el objeto cotidiano descontextualizado, junto a los detritos del propio artista, comenzarán por entonces a ser los ingredientes para componer tesoros íntimos, expuestos en pequeños estuches de cartón como venerables reliquias. De estos relicarios, fe-

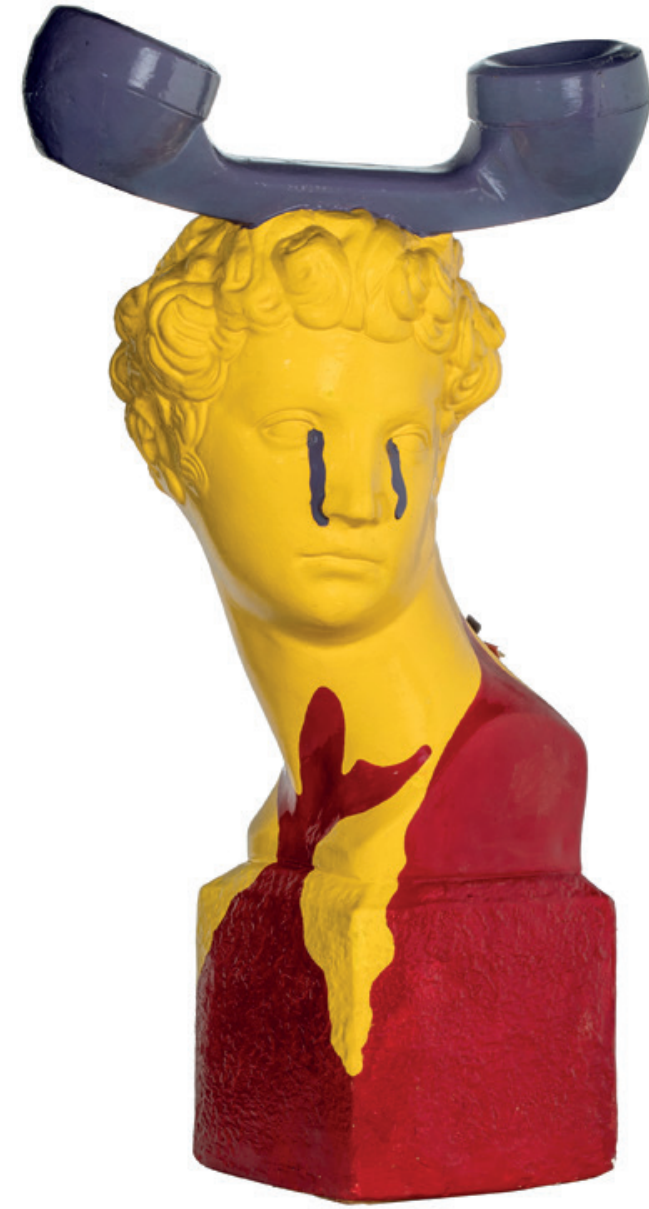

Fig.02. Toro lbérico, 1981. Escultura con objetos recuperados, $40 \times 21 \times 16 \mathrm{~cm}$. chados en 1985-86, hubo una buena muestra en la exposición que aquí analizo. En ellos aparece ya esa devoción hacia las cajas o contenedores de orden y espacio racionalizado que van a caracterizar su obra futura.

Quiero destacar, por su marcado carácter autobiográfico, ese busto del "Toro ibérico" (1981), tan temprano, donde un david de Miguelángel envuelto en los colores patrios se corona de la imponente montera/cornamenta de un auricular telefónico. También son de este momento dos tempranas obras como "Aider les enfants" (1980), y "Un éxtasis para Bernini" (1980), anticipadoras de sus cuadros-paneles donde ensamblará con más apertura que en las costreñidas cajas, objetos encontrados sobre fondos de materiales próximos al arte povera, tan propio del informalismo hispánico de entonces.

A la vez, esos años de la primera expansión económica de la democracia española vieron cómo Pradillo volvió, en su Antología 19 del año 1988, a la abstracción geométrica. La extensa colección ofrecida en esa nueva exposición fue resultado del trabajo realizado a partir de diecinueve dibujos matrices, y de las diferentes interpretaciones que permiten cada uno de ellos al recurrir a diversas técnicas y materiales -óleo, acuarela, collage y relieve escultórico-. Fruto de su creatividad, esperamos que estas series sean objeto deo volente de nuevas revisiones.

Pero el proceso prosiguió de forma imparable: en 1996, en la muestra In\Con.Vertido antes citada, había continuado con la construcción de cajas que, pese a su forma hermética, superaban el encorsetamiento del surrealismo onírico más primitivo. Todo en medio de los elogios del público y de la crítica. Como más arriba comenté, tuve el privilegio de glosar la exposición en el catálogo, Pedro José Pradillo. In\Con.Vertido, piezas que, todavía a falta de un programa ideológico co- 
mún, manifestaban ya el carácter neo pop -hoy optamos por el genérico término conceptual ${ }^{8}$-, de obras propias de la moda entonces vigente del reciclado, a partir de los desechos de contenedor, y sobre todo de una educación visual basada especialmente en la imposición de la televisión como medio de adoctrinamiento de las masas, de lo que se hacía eco nuestro autor.

Al tiempo, tanta incardinación con la actualidad se veía conectada con unas raíces dadaístas que partían claramente del culto de Pradillo al mítico Kurt Schwitters, el más dadá de los dadaístas. Resulta llamativo que de los dos libros de autor -o libros con valor y formato de obra de arte-, editados por Pradillo hasta la fecha, el primero fuera el del año 1992 titulado " 4 x KS = 0", Madrid, Colección 'La Media Vaca', 41. Es un documento que resulta en su marginalidad un verdadero homenaje a la memoria del artista de Hannover (1887-1948), aparte de ser un producto típico de aquel momento tan sobrevalorado de la Movida madrileña de los años del "pelotazo". Ahí en sus ocho páginas, se ve al Pradillo más neodadaista?.

Algunas obras de entre los ochenta y los noventa -sin afán de desmerecer a las demás-, eran ya importantes, merecedoras del aprecio del entendido y prontas a adquirir el carácter de piezas clásicas de un neovanguardista como Pradillo: ¿qué decir de ese estremecedor "Marat asesinado" (1985), donde impúdicamente se exhibe el cadáver momificado de un pollo despatarrado sobre una máquina calculadora oxidada? También admiramos ese "Gran Hotel/Caja de Música" (1996), de varios tenedores, donde el constructivismo pradillesco alcanza una de su cimas, y se anticipa veinte años a varias de las cajas objetuales del proyecto Besos y Caprichos, tanto en forma como en intención, con la genial asociación de los conceptos hotel-gallinero-estantería-lupanar. Por último, la instalación del "Rapto de Europa" (1996) sabe conciliar categorías conceptuales e intelectuales de marcado posmodernismo, con esa cita local expresada en el cartel de toros, y el asunto entre mitológico y geopolítico de los avatares del, más que viejo, acabado continente. En todas estas piezas funcionan el apropiacionismo del que participa Pradillo, la cita culta, y la continua referencia a la historia del arte occidental, aspectos todos que van a explosionar en creatividad en los últimos proyectos de la madurez de nuestro artista.

8. Sobre el arte conceptual es muy recomendable consultar, por ser coetánea con los primeros planteamientos del "estilo", la antología de BATTCOCK, G. (ed.) (1977), original que apareció en 1973 con el título Idea Art. A Critical Anthology, New York. El compilador plantea que las obras conceptuales se oponían a la idea del arte como objeto de consumo, y se oponían también a las orientaciones estéticas tradicionales, pues los aspectos técnicos de siempre eran absolutamente inútiles al ser aplicados a la nueva forma artística. El mismo público del arte conceptual experimenta ideas en lugar de ejercer sus facultades críticas sobre el propósito de los objetos. Asimismo señala que no se trata de un arte popular, puesto que su interés está más no en lo que es en sí, sino en los cambios que engendra. También es aconsejable MARCHÁN FIZ, S. (1972).

9. El segundo libro es una obra deliciosa de once páginas, titulada Tres lecciones de arte para Antonio Saura, Guadalajara, 1997, en la que Pradillo se atreve con descaro a hacer una feroz crítica del grupo Informalista español. Cierto es que el contenido de este libro ya se elaboró en el año de 1985 .

Umática. 2020; 3:113-134 
Fig.03. Marat asesinado, 1985. Escultura con objetos recuperados, $37 \times 44 \times 25 \mathrm{~cm}$.

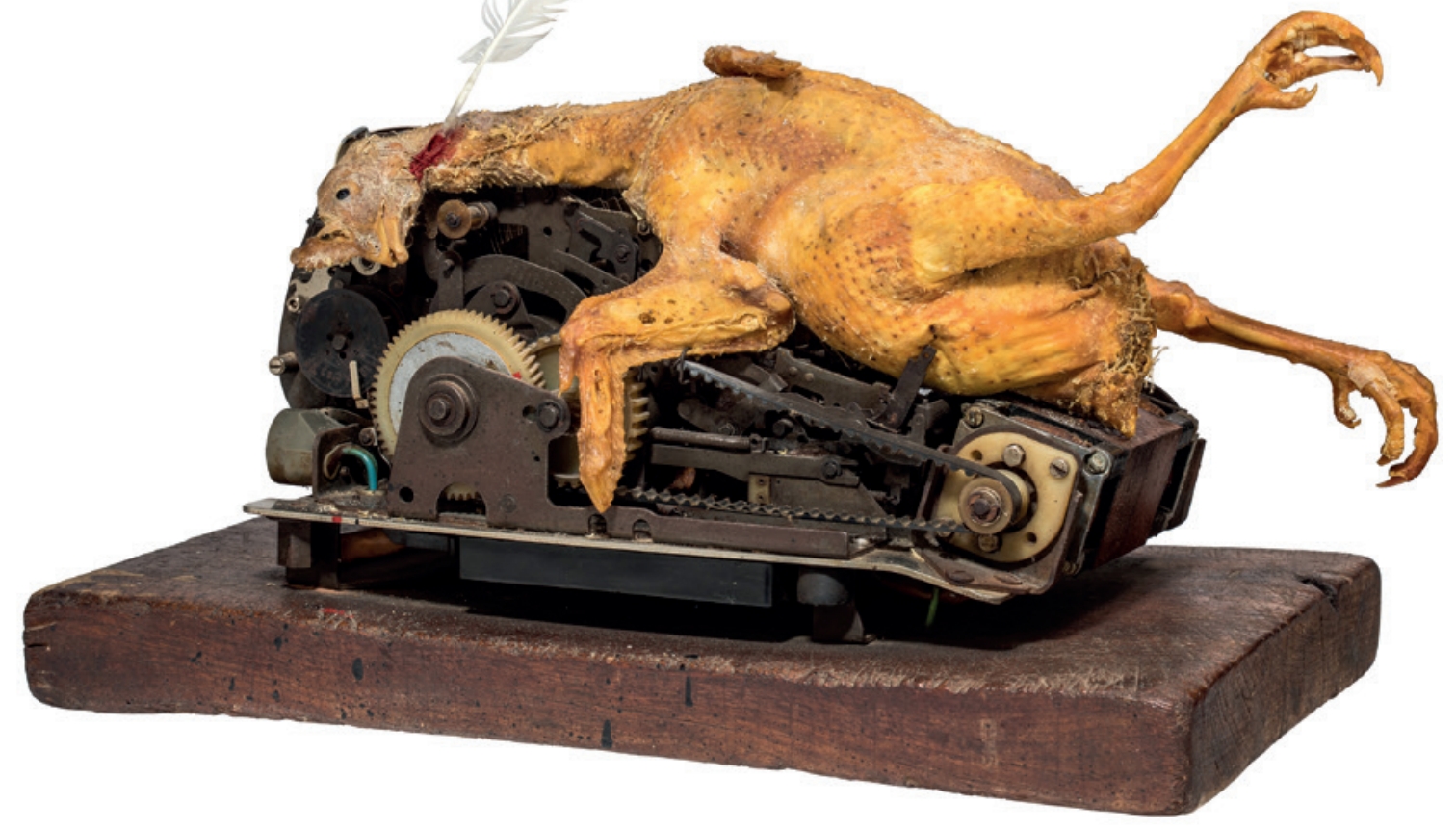

Como historiador debo señalar que al enfrentarnos con la obra última de Pedro José Pradillo, y dada la patente aceleración de los cambios perceptibles en la actual oleada tecnológica y social que nos envuelve, siempre nos será obligado hablar del "neovanguardismo" del arriácense, como algo específico que habrá que recuperar, tal vez por ya perdido, para seguir avanzando hacia adelante sobre unos pocos puntales firmes que sostengan su progresión.

El itinerario artístico de Pradillo se completa con sus dos proyectos más recientes y simultáneos, entre los años 2014-2018, y que también estaban suficientemente representados en la exposición que comento: el citado "Besos y Caprichos" y "Ecce-Homo. A propósito de Nietzsche"; abordados ambos después de un paréntesis vacuo, quizás demasiado prolongado, $y$, ahora, atizados por la desoladora coyuntura que ahoga los compases iniciales del siglo XXI. En ellos Francisco de Goya, Danilo Kiš, y Friedrich Nietzsche son el pretexto para concebir y elaborar otras dos colecciones objetuales de cajas y ensamblajes en las que prevalece el sentido narrativo y el enunciado retórico, a través de aforismos que denuncian los excesos de la sociedad con una acidez despiadada, y que reniegan del pretendido confort vociferado desde las élites.

Pero antes de comentarlos, digamos unas palabras sobre el citado movimiento apropiacionista: el apropiacionismo aparece no para representar la realidad mediante una figura, 
sino para re-contextualizar trabajos anteriores, buscando el significado de la obra. Los artistas apropiacionistas no ofrecen una apariencia, ni siquiera una imagen que represente la realidad, sino que buscan el impacto por lo que expresan con sus obras. Prima el elemento de la narración, con una necesidad del soporte digamos literario de gran intensidad, con tanta o más que lo que se pudo percibir en otros estilos históricos o de vanguardia, como fueron el romanticismo, el expresionismo y el surrealismo.

Con esta corriente la polémica sobre los derechos de la propiedad intelectual ha aumentado exponencialmente, pero en lo que atañe a Pradillo podemos estar muy tranquilos: en esta época que Walter Benjamin ya definió como la de la reproducción mecánica del arte, el alcarreño más que apropiarse-siempre se trata de objetos más buscados que encontrados, con preferencia por los no artísticos, para reconvertirlos, invertirlos y convertirlos en otra cosa-, lo que busca es cambiar los códigos denotativos del nuevo objeto, de la nueva obra a la que el filtro del tiempo y de la crítica acabará por considerar como arte, o como no-arte, por sus valores de calidad, originalidad y, por qué no decirlo también, de belleza, o mejor de rara belleza, en el sentido neo-manierista.

\section{Los dos grandes proyectos "Besos y Caprichos" y "Ecce Homo. A propósito de Nietzsche"}

Es de lamentar que del proyecto dedicado a los Caprichos de Francisco de Goya, tan lleno de calidad, en esta muestra antológica -por razón de su acomodación a las características de espacio e iluminación de la sala en que se exhibían-, sólo hubo ocho de las ochenta cajas-collage que Pradillo produjo con denuedo a lo largo de los años 2014-2018. Obra extensa, ha dejado anonadados a todos los que a ella se enfrentan. Como más arriba se dijo, el gran número de piezas de este ciclo ha llevado a su exposición parcial en varias muestras, ante la dificultad de exponerlas todas juntas, al menos de momento.

El día en que ello se logre se constatará la magnitud del esfuerzo de nuestro autor, capaz de engarzar con sutiles relaciones -como hizo Goya con sus estampas-, la práctica totalidad de sus componentes. Se verá entonces cómo la obra de Pradillo evoluciona de lo objetual a lo conceptual, ascendiendo a un nivel más alto de sabiduría.

Conviene destacar que las primeras creaciones de la serie Besos y Caprichos formaron parte de algunas exposiciones colectivas enmarcadas bajo el fenómeno del "Nanaísmo", intento de definir y alentar un nuevo y singular movimiento intuido por la percepción del marchante madrileño Manuel Marqués desde su gabinete artístico "Modus Operandi", en una línea entre lo neodadá y lo neosurrealista, a la que también está próxima la figura del escritor Fernando Sánchez Dragó. También se vieron en número reducido en el certamen Jazz Madrid del año 2016, y en apretado conjunto en la exposición individual del ayuntamiento de Móstoles, antes citados.

Ahora, para ayudar al lector a entender el método de trabajo pradillesco y los principios básicos de su obra conceptual, me atrevo a referenciar mis apostillas a una de las ocho ca- 
jas-ensamblajes de Besos y Caprichos presentes en aquella exhibición de 2019. Son glosas que forman parte de un libro monográfico sobre este ciclo, de reciente publicación ${ }^{10}$ :

\title{
Caja 43.- EL SUEÑO DE LA RAZÓN PRODUCE MONSTRUOS, 2018
}

\author{
Sé consciente del hecho de que la imaginación es hermana de la mentira, y \\ por ello mismo es peligrosa. Danilo Kiss.
}

Caja de madera pintada en rojo burdeos con frontales de metacrilato. En la trasera, ilustración de la edición italiana de El Quijote de la Mancha de Salvador Dalí (1964) con un muñeco de barro en el interior del tronco, y frases para la edición de los Sueños.

Interior: Figura Robocop del largometraje de Paul Verhoeven (1987) y del leopardo de cartón de El jardín del Edén de Jan Brueghel, El Viejo (1610-1612). En el fondo, botellero de madera con murciélago de bronce, el consejo, cromo del aguafuerte, mariposa de papel, ídolo precolombino, torreón de piedra, otras figuras y elementos, y recorte coloreado del aguafuerte El sueño de la mentira y la inconstancia.

\section{"La fantasía abandonada de la razón, produce monstruos imposibles; uni- da con ella, es madre de las artes y origen de sus maravillas" (Manuscrito. Museo del Prado)}

"Portada para esta obra: cuando los hombres no oyen el grito de la razón, todo se vuelve visiones" (Manuscrito. Biblioteca Nacional)

Junto al autorretrato de la portada y al grabado Volaverunt, no cabe duda de que este también retrato del artista, entre dormido y deprimido, es una de las estampas más importantes en simbología y estética para compendiar la esencia de los Caprichos. Quizás por ello encontramos en el dibujo preparatorio más próximo a la versión definitiva el pensamiento que explica con palabras del mismo Francisco de Goya. la clave de tan magna obra: "El autor, soñando. Su intento solo es desterrar bulgaridades perjudiciales, y perpetuar con esta obra de caprichos el testimonio sólido de la verdad".

Dicho esto -además de afirmar que en un primer boceto del huecograbado el aragonés nos ofrece una de las visiones protosurrealistas más prodigiosas con el juego sutil de su rostro, repetido a modo de efluvio plástico que surge de su atormentada cabeza-, todos los expertos en la serie afirman que en un principio Goya pensó en emplear este grabado como portada de la serie. 
Luego cambió de opinión, y la situó en la zona intermedia de la misma. Pradillo le ha prestado la importancia merecida.

Es obligado analizar objetivamente el resultado de la multifacética -y espectacular no sólo por su gran tamaño-, pieza pradillesca: paralelepípedo de madera abierto por los dos lados frontales con la transparencia del metacrilato, una rejilla de 24 cuadrados actúa a modo de elemento ordenador, en su ortogonalidad, del espacio. Un panel de madera en el ángulo inferior derecho ocupa el sitio de la mesa donde se reclina el pintor, mientras que las casillas sirven a modo de aparador para colocar piezas y figurillas inconexas de diversa plasticidad. Elementos gráficos, esculturas de pequeño tamaño, a modo de baratijas, una mariposa fotografiada que alude, como la vecina cabeza de la vieja y la maqueta de torreón, a el Sueño de la mentira y la inconstancia-aguada que varios autores consideran iba a formar parte de los Caprichos-, y, por último, destaca el monstruoso murciélago que se ha visto en otras láminas de la carpeta.

Sobresale también como figura clave la imagen pop de Robocop, icono posmoderno que como el Golem, el monstruo de Frankenstein y toda la infinidad de quimeras, es el modelo escogido entre muchos otros posibles para encarnar la pesadilla engendrada por la razón, o también por su ausencia o sinrazón. A sus pies, en vez del gatazo brujeril del grabado goyesco, una de las panteras de 'merchandising' - propio de una tienda de museo- en figura de cartón para montar en tres dimensiones. Banalización de una de las más bellas representaciones de la escuela manierista de Amberes, centrada en el Paraíso, el perdido por la caída de los primeros padres. Temática pues propia de una interpretación religiosa al tiempo que histórica de la raza humana, jardín primigenio, pérdida de la inocencia, necesidad última de la redención que sólo la Encarnación nos asegurará. Esta es entre otras la idea-fuerza del film de Verhoeven (1987), en el que se muestra que sólo el policía Murphy, muerto y resucitado, era quien poseía reales ideales de justicia y rectitud, necesarios para luchar en el Detroit finisecular contra el poder urbano, el de las corporaciones, de las mafias organizadas convertidas en terroristas o viceversa, la búsqueda de la reducción de gastos con la quimera de las máquinas, los paralelos entre la publicidad y la información... y muchas cosas más. Es así Robocop, versión libre del Salvador, digno de convertirse seis décadas más tarde en novio de la inolvidable María, habitante de la 'Metrópolis' futurista de F. Lang. En la parte trasera, homenaje al maestro de Cadaqués, y a esa primera novela moderna en la que tantas vueltas se da a la mezcla de fantasía y razón -madre de todas las artes-, pero que si no van de la mano sólo producen monstruosidades. Una obra, como todas las de nuestro autor, excelente y polisémica, aunque al dejarse llevar por la mitificación del séptimo arte y las películas 
Fig.04. Ecce-Homo, 2016. Escultura con objetos recuperados, $20 \times 28,5 \times 20 \mathrm{~cm}$. de culto, podría recordársele a Pradillo que otro eximio alcarreño, de nombre Buero, supo ver a partir de este mismo grabado a un Goya que se convertía en autor y espectador al tiempo de y en su misma obra. El sabio consejo de Danilo Kiss lo explica con precisión.

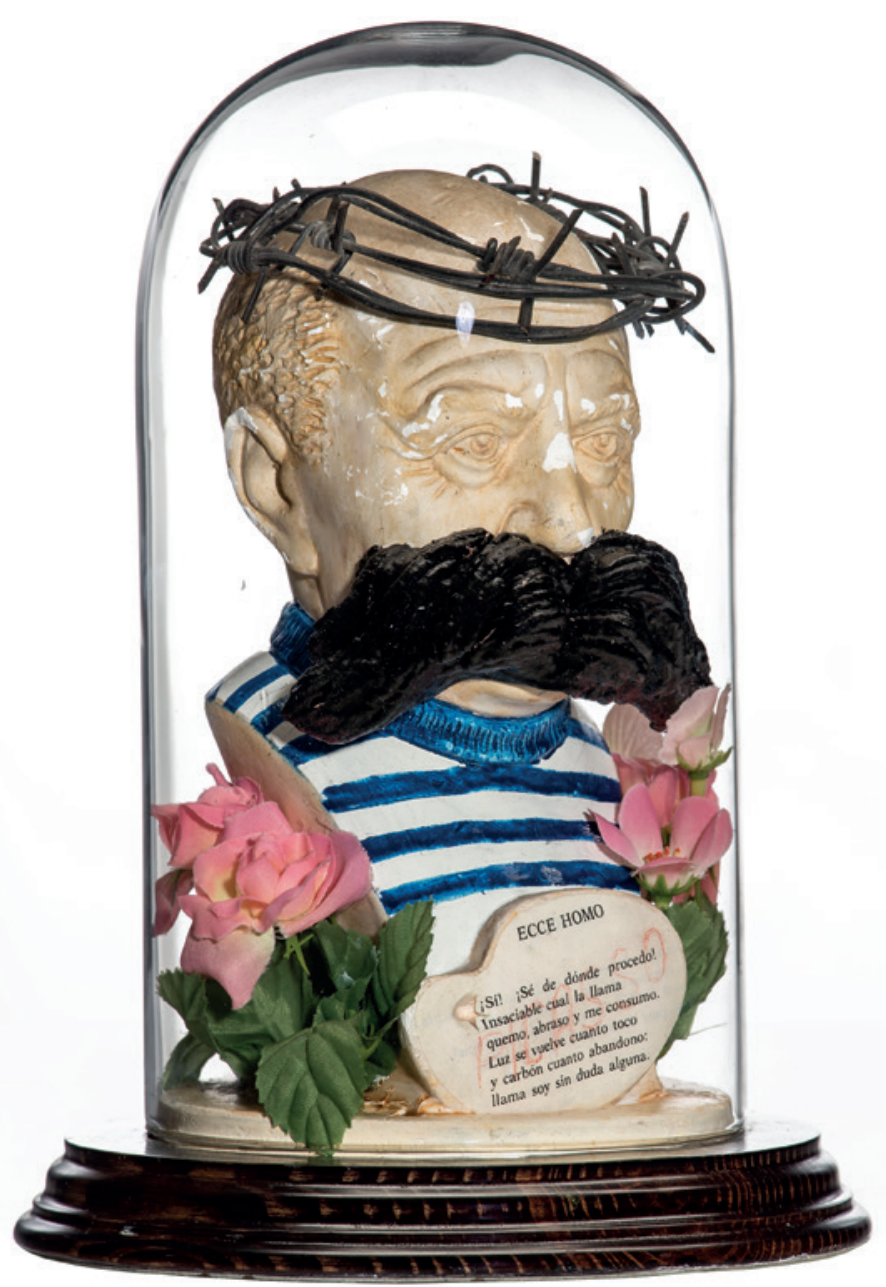

Otras claves detectadas a nivel general en el proyecto de Besos y Caprichos, podrían ser las siguientes: en nuestro citado estudio sobre la serie ${ }^{11}$ se ha demostrado que el color, como cualquier otro elemento plástico sea cual sea su naturaleza, nunca es inocente en el discurrir pradillesco por la vía de la sátira. Al tiempo, lo aleatorio o azaroso encuentra muy poco espacio en su empresa fundamentalmente moralizadora.

Asimismo el análisis formal del aspecto exterior de las cajas-collage de Pradillo, se debe completar dirigiendo la atención hacia otras presentaciones matéricas de muchas vitrinas que se cierran con madera, en su color o barnizada, o cubierta ésta con forros de muy variada textura, como hule, plástico, papel de aluminio, papel pintado de envolver, telas naturales

11. MUÑOZ, J. M. (2020), pp. 9-29. 
o artificiales, encajes, arpilleras, pegatinas, papel de periódico, etc. En otras se ha recurrido al metal -los clichés de imprenta de motivos geométricos son muy utilizados-, al plástico, al cristal, e incluso en dos o tres ocasiones a la piel animal, sintética o natural, en un curioso proceso de animalización y de antropomor fismo -como en una caja con piernas-, de algunos de los ochenta escaparates. Pero al margen del recurso exterior a fotografías, y a grabados fotocopiados y manipulados con valor icónico, los citados materiales de cubrición también son empleados exhaustivamente en los interiores de las cajas, en las "paredes" del escenario teatral que tantas veces se crea gracias al paralelepípedo.

En las obras del último Pradillo queda patente que nunca deja nada al azar, sino que su creatividad es altamente consciente, fruto de cerebración; y que es claro que cuanto más inocente parezca el exterior del envoltorio, más ácido será el contenido encerrado entre las paredes del hexaedro, que funciona como papel de caramelo o regalo envenenado, a veces con finalidad simbólica.

El corta y pega, principio del recortable, es realizado por la mano del artesano, pero ha de ser dirigido por la mente del artista. En esta línea, quiero poner un ejemplo de cómo la textura del exterior de uno de estos escaparates presentes en la citada muestra de 2019 es significativa, incluso aunque no quiera parecerlo: en una de las obras más cornellianas -como es la caja 53, y no sólo por la presencia de la cacatúa-, nuestro autor opta por una, más que sobria, pobrísima caja de madera sin tratar para encerrar uno de sus mejores dioramas, el dedicado a la Sagrada Familia de Gaudí; el gesto de desatención del envolvente sólo puede deberse a una actitud de desprecio hacia la arquitectura del genio barcelonés. Algo parecido podría haber en la obra 76 , en contra del militarismo, asimismo expuesta en la misma antológica.

También, en ese escrutinio sobresalen cerca de una decena de procedimientos plásticos de patente origen en la cultura de masas en su más amplio sentido, muchos ya vistos en maestros del llamado Pop-art, y que serían los siguientes:

- Atención explícita a los massmedia en cualquiera de sus formatos, a las noticias que difunden y al modo de tratarlas, nunca ingenuo ni inocuo.

- Devoción por el séptimo arte, con la utilización escogida de fotogramas de películas de culto.

- Inspiración formal en los anuncios publicitarios, que indudablemente también fagocitan modos artísticos.

- Manejo exhaustivo de historietas, tebeos y comic, como elementos populares de expresión gráfica.

- Empleo de objetos culturales descontextualizados, en ocasiones con una apariencia kitsch conscientemente buscada.

- Aparición de colores, texturas y otras referencias de la estética pop.

- Manipulación de reproducciones de obras de arte tradicional y de vanguardia.

- Referencias explícitas a la pornografía.

- Empleo ocasional de fotografías antiguas.

- Aparición de elementos desagradables o tétricos. 
Fig.05. El sueño de la razón produce monstruos, 2018. Caja con objetos recuperados, 51,5 $\times 35 \times 22 \mathrm{~cm}$.

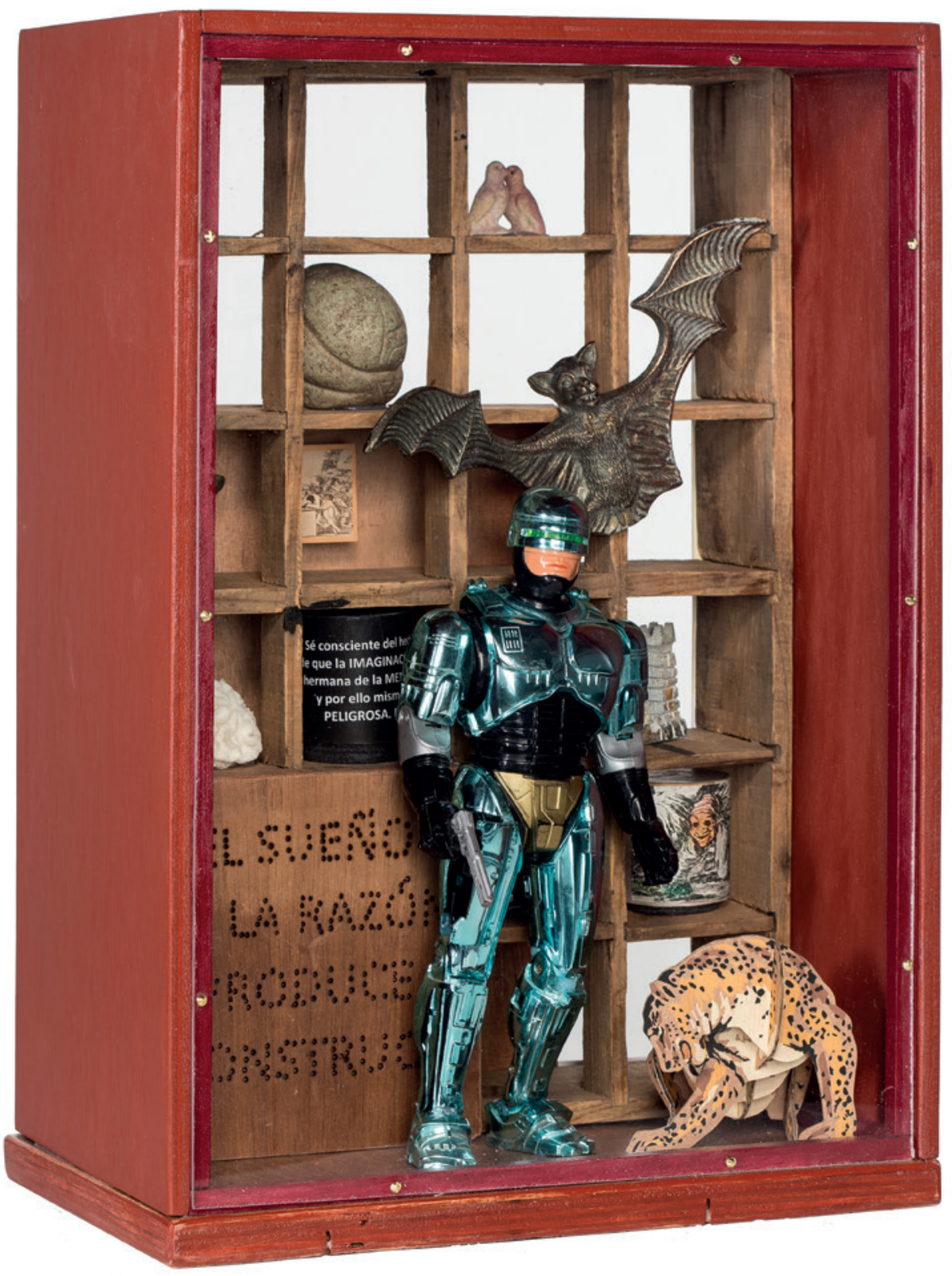

Quiere decirse que al contemplar las cajas de Pradillo es perceptible que en la mayoría de ellas lo habitual es el uso de una estructura basada en: 1. la colocación en el centro y primer plano del escenario de figuras grandes -en relación al tamaño no excesivo de los contenedores-, de tres dimensiones; 2 . que se rodean de fotos y dibujos en los lados, y $\mathbf{3}$. que se cierra con un motivo principal de poco relieve, por detrás.

Pero debe saberse que ese mecanismo de enfrentamiento "adelante/atrás" no es, ni mucho menos, el único. Pues, por ejemplo, son varios los casos en que se ha renunciado expresamente a dotar de uso icónico a la parte trasera de la pieza 
Así, en una propuesta tan rica como la de los Besos y Caprichos, que está basada en el continuo confrontar, son varios los juegos relacionales visibles en los espacios creados por un artista tan lúdicro como Pradillo. Insisto en que el gran modo, por tratarse básicamente de poliedros y paralelepípedos, es ese sentido direccional "desde afuera hacia adentro", fundamentado en el punto de vista del espectador como ocurre con casi todas las artes visuales, pero también en el uso como superficie de exposición de los laterales del hexaedro, y sobre todo -aunque no siempre-, de su pared trasera.

Formalmente se trata de una historia, en cada caja, contada por capítulos, cuya conclusión suele hallarse, repito, en la parte posterior. Puede verse una variación del número de actos, siendo raras las obras de un único momento, predominantes las de dos, y más raras las que se deben leer en tres o más pasos.

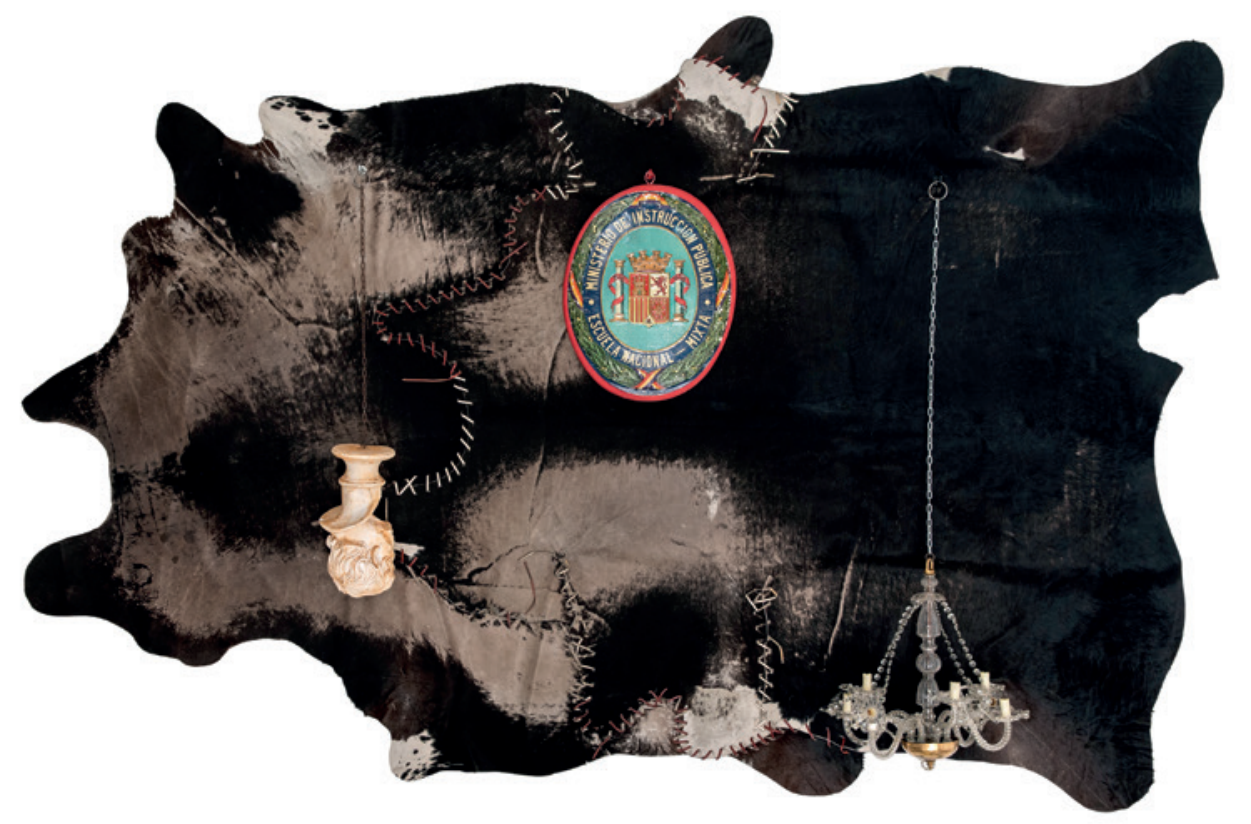

Es claro que ante la obra de Pradillo es obligado mezclar los aspectos de la composición espacial, con los análisis de intencionalidad simbólica. Pues la clave de su conceptualismo radica, como más arriba se dijo, en que en ella nada es casual, ni azaroso, sino que por su racionalismo de origen ilustrado todo está pensado y sopesado.

Ello derivaría en que, como en los Caprichos goyescos, tanta variedad se unifica sin duda por el afán de lo satírico, género literario de muy antigua progenie, que siempre se basa en la censura o ridiculización de algo o de alguien ${ }^{12}$.

12. Recordemos la ferocidad rabelesiana o quevedesca. De las letras, la sátira pasó al género teatral y al artístico, y la corriente alcanzó un momento de esplendor con la llustración dieciochesca. En especial con la británica, pero también con autores italianos.

Umática. 2020; 3:113-134
Fig.06. Nostalgia de qué, 2019. Ensamblaje con objetos recuperados, 230 $\times 350 \times 60 \mathrm{~cm}$. 
Cabe pensar que por haber seguido además, como segunda línea de inspiración, las para él excelentes lecciones que se derivan de los "Consejos para un joven escritor" del poeta Danilo Kis, el laberinto conceptual se refuerza en grado máximo, con escasas posibilidades de escape.

A modo de conclusión semántica, pero también en su plano estético, muchos de los embalajes de nuestro conceptualista autor obligan al espectador a manipular y rodear el fardo, buscándole las vueltas. Encontrará además en ellos objetos reales tridimensionales, fotogramas y figuras de marcada planitud e inconsistencia, así como visiones ópticas al otro lado de la luna de cristal y azogue.

Ante este pie forzado nos interesa ver cómo Pradillo obedece a la ordenación del modelo que se auto impone, pero sobre todo cómo va logrando variedad de interpretaciones -en el fondo y en la forma-, de sus cultos acertijos. Unas veces más parecen jeroglíficos, otras más, sencillos crucigramas; pero siempre nos muestran el conocimiento que tiene su autor de la sociedad del presente y del pasado. Visualmente son ricos en propuestas en las que el concepto se mimetiza con la anamor fosis manierista, la analogía con lo mediático, y lo expresionista con el dadá y el surrealismo.

Se trata pues de una apuesta estética de extremo subjetivismo -en la que se alcanzan los límites de la técnica del collage objetual-, en la que la continua dicotomía entre Goya y Pradillo, con la herencia de Dalí y la sabiduría de Kis como estrellas invitadas, alcanza su paroxismo en la lucha entre el continente y el contenido. Al final, si hubiera que resumir en una sola imagen todo este fecundo empeño, toda esta tarea, quizás la más precisa sería la de una sección célebre de la vieja revista La Codorniz que se titulaba "La cárcel de papel": un calabozo en el que Pradillo ha metido a múltiples personajes, pero en el que, al visitarlo, puede también quedar prendido y prendado el espectador.

Respecto al segundo ciclo de los años 2017-2018, titulado "Ecce-Homo. A propósito de Nietzsche" y formado por dieciséis piezas, hubo en la exhibición de Guadalajara de septiembre de 2019 nada menos que siete de ellas, por un lado por acomodarse en su nuevo formato de cuadro o plafón-ensamblaje más adecuadamente que otras al recinto expositivo de aquella ocasión; pero también por el aprecio que el propio autor concede a esta serie, que indudablemente quedaba así muy bien representada.

En una apretada síntesis, seis serían los puntos fuertes de la temática del sajón a los que se enfrenta Pradillo y nos enfrenta a nosotros y a nuestra época: el irracionalismo vitalista; el espíritu de la tragedia como suma de lo apolíneo y lo dionisíaco; la voluntad de poder; la transmutación de todos los valores; el superhombre, y el mito del eterno retorno.

Con Nietzsche, que también fue como Pradillo un salvaje irredento, se comparte una manera de ver el mundo al tiempo rebelde e integrada, pues el primero, el de la fama de nihi- 
lista, también fue capaz de formular una idea tan esperanzadora como ésta: "Quien tiene un por qué para vivir, puede soportar casi cualquier cómo".

Por razones de espacio me limito a reproducir mis comentarios ya publicados ${ }^{13}$ a una de las obras sobre el proyecto "Ecce Homo" allí expuestas, por ser como el cartel -dado su carácter de autorretrato-, de aquellas muestras que recorrieron diversas ciudades españolas:

\section{Ecce-Homo}

A modo de prefacio o portada de la quincena larga de obras que conforman esta interpretación pradillesca de la filosofía del genial prusiano, nos encontramos con este pequeño contenedor en forma de fanal protector, de los utilizados tradicionalmente para exhibir imágenes religiosas o delicados adornos florales. En su interior, la febril imaginación de Pradillo ha parido una especie de teriántropo monstruoso, más manierista que pleistocénico, que convierte un busto de Pablo Picasso -el padre reconocido de la revolución cubista-, en "un" Nietzsche, al dotarlo de un enorme bigotón.

Además de un poema del filósofo, el conjunto se corona provocativamente con una corona de espinas de alambre, recurso de pobreza que quien esto escribe ha llegado a ver en la cabeza de algún Cristo barroco de las míseras iglesitas del trópico panameño. Tampoco faltan las flores de plástico en rendido homenaje, ni la clara intencionalidad de señalar cómo, ambos personajes fundidos en uno, han sido según Pradillo "de los más influyentes en el pensamiento occidental del siglo XX, por sus ideas y propuestas revisionistas".

Se trata en suma, de una imagen de lo más impactante y sobrecogedora, en especial por la asombrosa economía de medios utilizada para expresar tantas ideas originales. Nótese el recurso reiterado a un lenguaje y a unos elementos propios del discurso cristiano, del que Nietzsche es una y otra vez un pobre opositor, en su afán de encarnar al Anticristo. Aunque haya que dejar hablar a la obra, no olvidemos que esta pieza es también, en mi opinión, un autorretrato de nuestro autor.

Hay que concluir que Pradillo, con su ya ensayado sistema narrativo, ha tratado en este ciclo de tú a tú al que fue llamado por Ricoeur "maestro de la sospecha"14. Al final de su em-

13. MUÑOZ, J. M. (2018).

14. RICOEUR, P. (1965). Aunque desde diferentes presupuestos, según este autor, los tres filósofos de la duda consideraron que la conciencia en su conjunto es una conciencia falsa. Así, según Marx, la conciencia se falsea o se enmascara por intereses económicos, en Freud por la represión del inconsciente y en Nietzsche por el resentimiento del débil. Sin embargo, lo que hay que destacar de estos maestros no es ese aspecto destructivo de Umática. 2020; 3:113-134 
presa nietzschiana se puede asegurar que, como a su referente filosófico, le mueve una profunda herencia ilustrada, en la que lucha con denuedo la doble faz del pathos occidental, entre la razón y la pasión.

\section{Conclusión:un arte culto para pensar. Neo-POP y Post-posmoderno}

Después de analizar con atención la carrera artística de Pedro José Pradillo, hemos de concluir en que hay artes para gozar y disfrutar y artes para pensar. El alto valor del sistema narrativo de las propuestas de Pradillo, resumidas con suficiencia en la exposición antológica de 2019 en Guadalajara, pertenece a esta segunda modalidad. Como señaló uno de los críticos periodísticos al reseñar la muestra, ahí se encontraba la paráfrasis "de una vida, y de una patria". Cabe asegurar asimismo que hoy en día Pedro José Pradillo es uno de los nombres más importantes del Conceptualismo español.

Otra conclusión sería que la principal característica que se observa en la madura producción de este artista, al margen de sus períodos constructivistas, es su fidelidad al arte conceptual y objetual; también el profundo análisis que aborda sobre el significado del arte - en particular del elaborado en el siglo XX-, y acerca del papel de la cultura en la sociedad occidental. Su interés, como en cualquier otro artista de ese movimiento, se centra en lograr imágenes y objetos para la fascinación, a partir de la combinación de elementos encontrados que, más allá de la particular estética resultante, susciten inquietudes no deseadas en el espectador y provoquen en él motivos para la reflexión.

Todas sus creaciones, como las aquí comentadas, presentan una visión transversal y caústica de su tiempo, crítica con el individualismo neoliberal imperante, e incrementan la visibilidad de ciertos problemas subyacentes que preocupan a muchos. Pero, además, para acrecentar los efectos de esta acción de denuncia el autor emplea como recursos efectivos la ironía y el cinismo, a veces presentados bajo la envoltura de lo lúdico. También se burla de la estulticia generalizada en el dominio actual de lo políticamente correcto, así como de la tiranía que los mass-media ejercen sobre una sociedad de analfabetos funcionales.

Quizás se trate simplemente de una post-posmodernidad, en la búsqueda agitada que se aprecia en este artista porque no se llegue, al final, a esa post-verdad que parece estarse hoy imponiendo. Pues, sabemos con él, que ello sólo puede conducir a la nada. Por ello deseamos que el esfuerzo de Pradillo sirva para evitar, si fuera posible, la definitiva rebelión de las masas ignorantes.

las ilusiones éticas, políticas o de las percepciones de la conciencia, sino una forma de interpretar el sentido. Lo que quiere Marx es alcanzar la liberación por una praxis que haya desenmascarado a la ideología burguesa. Nietzsche pretende la restauración de la fuerza del hombre por la superación del resentimiento y de la compasión. Freud busca una curación por la conciencia y la aceptación del principio de realidad. Los tres tienen en común la denuncia de las ilusiones y de la falsa percepción de la realidad, pero también la búsqueda de una utopía. 


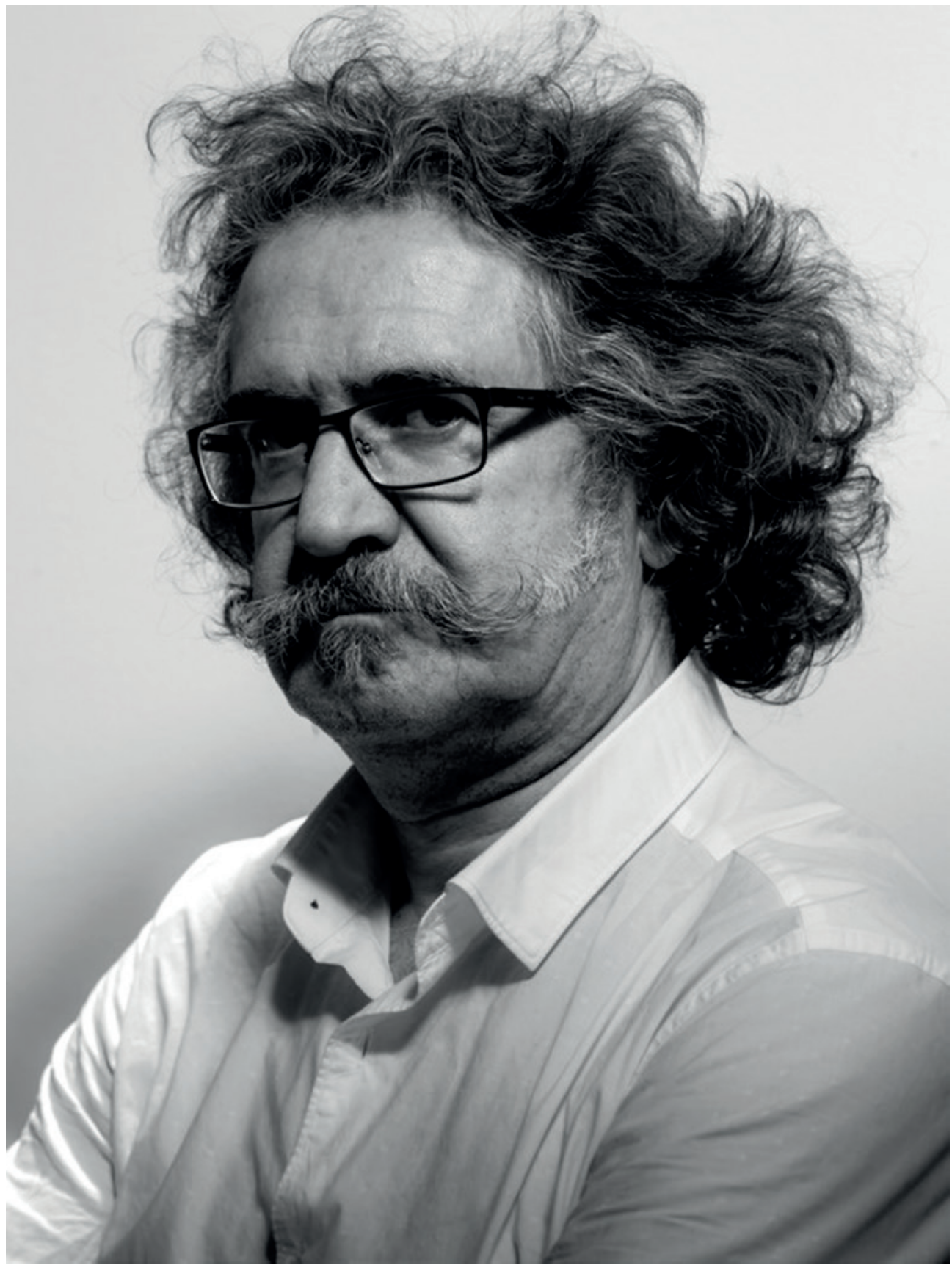

Fig.07. Retrato de

Pedro José Pradillo 


\section{Referencias}

BATTCOCK, Gregory. (ed.) (1977). La idea como arte. Documentos sobre el arte conceptual, Editorial Gustavo Gili, Barcelona.

BURNHAM, Jack (1976). "Problemas críticos", La idea como arte. Documentos sobre el arte conceptual, Editorial Gustavo Gili, Barcelona, pp. 43-59.

KoSUTH, Joseph (1969). "Arte y Filosofía I y II", Studio International, diciembre.

MARCHÁN FIZ, Simón (1972). Del arte objetual al arte de concepto, Editorial Alberto Corazón, Madrid.

MUÑOZ JIMÉNEZ, José Miguel (1996). "Cajas, Dadá y Neo Pop", en el catálogo Pedro José Pradillo.In\Con.Vertido, Guadalajara, Junta de Comunidades de Castilla-La Mancha.

MUÑOZ JIMÉNEZ, José Miguel (2018). 'Ecce Homo. A propósito de F. Nietzsche': la última propuesta del artista conceptual Pedro José Pradillo", Actas del XVI Encuentro de Historiadores del Valle del Henares, Alcalá de Henares, pp. 467-486.

MUÑOZ JIMÉNEZ, José Miguel (2019). "El arte como narración. Pedro José Pradillo, un artista conceptual", en el Catálogo de la exposición 'Con qué objeto', Guadalajara, pp. 5-17.

MUÑOZ JIMÉNEZ, José Miguel (2020). Besos y Caprichos. Iconografía y estilo en 80 cajas-collages de Pedro José Pradillo, Guadalajara.

PerREAULT, John (1971). "Solo palabras", en The Village Voice, 20 de mayo de 1971.

RICOEUR, Paul (1965), De l'interprétation: Essai sur Freud, Paris: Editions du Seuil. 